\title{
Chapter 6 \\ Particularities of the Legal Framework for the Mexican Emissions Trading System
}

\author{
Rosalía Ibarra Sarlat
}

\begin{abstract}
This paper examines the legal bases for the mandatory regulation of the emissions trading system in Mexico. They are derived from the main international instruments on climate change: the United Nations Framework Convention on Climate Change (UNFCCC) and its ambitious objective, the quantifiable commitment of the Kyoto Protocol, and its tie to economic instruments. The Paris Agreement, the Nationally Determined Contributions (NDCs) and the market mechanisms regulated in Article 6, the implementation of which is essential to achieve the Agreement's objectives are also part of this broad system. Legally, the international foundations of the emissions trading system are reflected at the national level. For these, the constitutional and legal bases underpin the current regulation of the mandatory market instrument. It aims to effectively reduce, in terms of costs, the greenhouse gas emissions from the most polluting economic activities, without replacing direct control measures. The core aspects of this system are highlighted from a national regulatory analysis, with special emphasis on the importance of a limited cap and its future reduction, as well as the legal nature of allowances that are allocated by the public administration to the regulated industries' facilities.
\end{abstract}

Keywords Emissions trading $\cdot$ Economic instruments $\cdot$ Emission allowances • Carbon markets $\cdot$ Regulations $\cdot$ Mexico

\section{Introduction}

The economic theory considers climate change as a negative externality derived from the burning of fossil fuels for industrial and energy production. To correct this great market failure and to internalize the externalities in the design of environmental public policies, the environmental economy plays a fundamental role as it consists of applying the economic principles to the study of natural resource management.

\footnotetext{
R. Ibarra Sarlat $(\bowtie)$

Institute of Legal Research (IIJ) of National Autonomous University of Mexico (UNAM), CDMX, Circuito Maestro Mario de la Cueva s/n. Ciudad Universitaria, c.p. 04510, México City, Mexico e-mail: ribarra@unam.mx
} 
This is accomplished by integrating the environmental variable into conventional economic analysis so that the structure of environmental decisions is based on costeffectiveness and cost-benefit considerations. In this regard, to mitigate greenhouse gas emissions, global and national interests have been strengthened by the adoption of economic instruments, especially carbon markets as complementary measures to command and control regulations to ensure global benefits at the lowest possible cost. The Mexican government is no exception. To achieve its emissions reduction goals, it has opted for the mandatory implementation of the emissions trading system in a cap and trade scheme, an instrument to promote energy efficiency, the introduction of new low-carbon technologies, investment in technological innovation, the modification of consumption patterns, etc., all aimed at decarbonizing our economy. The implementation of this instrument has legal backing at the international and national levels, which has been progressive in promoting the use of these systems, focused on improving their regulatory framework and broadening their scope in both jurisdictions.

Due to methodological issues and legal hierarchy, this paper starts from the study of the international instruments on which the regulatory regime on climate change is based, with special emphasis on certain particularities, such as in the case of the ambitious objective of the United Nations Framework Convention on Climate Change (UNFCCC); the quantifiable commitment of the Kyoto Protocol and its link to economic instruments; the Paris Agreement, the Nationally Determined Contributions (NDCs) and the market mechanisms regulated in Article 6 whose scope of application is still under discussion in international forums.

After analyzing the international foundations of the emissions trading system, its application at the national level is studied, which is reflected in constitutional bases and in the regulations pertaining to the economic instruments of the General Law of Ecological Balance and Environmental Protection (Ley General de Equilibrio Ecológico y Protección al Ambiental or LGEEPA) and the General Law on Climate Change (Ley General de Cambio Climático or LGCC), which support the current regulation of the emissions trading system in Mexico.

Finally, the analysis of the national regulations highlights the core aspects of the system, with special emphasis on the cap, as well as the free allocation of allowances and the polluter pays principle, to conclude with the importance of defining and identifying the legal nature of the allowances allocated by the public administration to the facilities of the regulated sectors.

\section{International Legal Basis}

The international legal regime for climate change is made up of three binding instruments to which Mexico is a State Party:

- The United Nations Framework Convention on Climate Change (UNFCCC) adopted in New York on 9 May 1992. In effect since 21 March 1994. 
- The Kyoto Protocol (Protocol to the UNFCCC) adopted in Kyoto, Japan, on 11 December 1997. In effect since 16 February 2005.

- The Paris Agreement adopted in Paris, France, on 12 December 2015. In effect on 4 November 2016.

\section{The Objective of the UNFCCC}

The main objective of the Kyoto Protocol and the Paris Agreement, as the Convention's legal instruments for its effective implementation, is stipulated in Article 2 of the Convention, which states that:

The ultimate objective of this Convention and any related legal instruments that the Conference of the Parties may adopt is to achieve, in accordance with the relevant provisions of the Convention, stabilization of greenhouse gas concentrations in the atmosphere at a level that would prevent dangerous anthropogenic interference with the climate system. Such a level should be achieved within a time frame sufficient to allow ecosystems to adapt naturally to climate change, to ensure that food production is not threatened and to enable economic development to proceed in a sustainable manner.

The achievement of the UNFCCC's objective is long term and requires the participation and collaboration of the various sectors involved in order to modify behavior patterns in strategic areas, such as energy and industry. The interests are many and diverse, the difficulty of which lies in making them compatible.

A key point is the sustainable development principle, adopted by the UNFCCC in accordance with its Article 3, from which it follows that efforts to prevent and combat the effects of climate change must not run counter to the economic development of countries, especially the most vulnerable ones, as long as it is not detrimental to the environment. This way, Parties must promote and opt for a sustainable economic development model so that the protection of the climate system is for the benefit of present and future generations. ${ }^{1}$

For sustainable development to be a viable proposal, economic, social, and political changes are needed at the international and national levels in which strategies respond to the interests of the majority and where a new order is sought, especially an economic one that promotes the rational and balanced democratic management of natural resources that guarantee peace, stability, and prosperity in the world community.

Under this scheme, sustainable development must be related to the simultaneous and ongoing evolution of the economic, social, environmental, technological, and political sectors at the international and national levels (World Resources Institute 1992). Its implementation implies a development that can be maintained in the long term from environmental and economic points of view through the use of less polluting technologies and with lower or no greenhouse gas (GHG) emissions.

\footnotetext{
${ }^{1}$ The Convention refers to the right to development, recognized as a human right in the Declaration on the Right to Development approved by Resolution 41/128 of the UN General Assembly on 4 December 1986.
} 
Emissions trading through effective implementation is, precisely, an instrument that can contribute to the achievement of this objective.

\section{The Quantified Commitment of the Kyoto Protocol and Its Link to Economic Instruments}

Stabilizing greenhouse gas (GHG) concentrations in the atmosphere at a level that would prevent dangerous anthropogenic interference with the climate system involves the adoption of quantified commitments to reduce total emissions by at least 5\% relative to 1990 levels for the 2008-2012 period. This is a core obligation of the Kyoto Protocol exclusively for developed countries and those with economies in transition (Article 3). For compliance and in order to promote sustainable development, each of the obligated Parties must implement and/or develop measures and policies for the progressive reduction or phasing out of market deficiencies, fiscal incentives, tax and duty exemptions, and subsidies contrary to the objective of the Convention in all GHG-emitting sectors, and apply market-based instruments (Article 2).

Agreeing on the commitments assumed in the Kyoto Protocol was possible thanks to the inclusion of three economic mechanisms, known as flexible mechanisms aimed at making it easier for the obligated Parties to meet the quantified emission reduction commitment at a low cost. These were proposed in previous negotiations by the United States Government:

(1) The Joint Implementation (JI), regulated in Article 6, allows governments and companies from developed countries grouped in Annex I of the UNFCCC (Annex B of the Kyoto Protocol) to invest in other countries of the same group in the realization of projects for emission reduction or carbon sequestration by promoting sinks, which is compensated by Emissions Reduction Units (ERUs).

(2) The Clean Development Mechanism (CDM), regulated in Article 12, is an instrument that promotes and regulates public or private investments by countries included in Annex I of the UNFCCC (Annex B of the Kyoto Protocol) in emission reduction or carbon sequestration projects carried out in a non-Annex I country (developing countries) to help it achieve sustainable development and contribute to the ultimate objective of the Convention, which is rewarded with Certified Emissions Reductions (CERs).

(3) The Emissions Trading (ET), regulated in Article 17, is a system that operates in a market based on an emissions limit and its trade (cap and trade system). The certainty of the results is based on the establishment of a total quota of allocated allowances, which represent the total limit of authorized emissions. Under this regime, UNFCCC countries party to Annex I (Annex B of the Kyoto Protocol) or those legal entities that they have authorized ${ }^{2}$ may trade through purchase

\footnotetext{
${ }^{2}$ At the time, the Protocol only perceived emissions trading between States, however, it was later admitted that States could associate their companies, without replacing State responsibility.
} 
and sale depending on whether they have emission surplus or deficit. The different types of accounting units are recognized by the Protocol (Assigned Amount Units-AAU, or those generated by projects, such as CERs and ERUs). The incorporation of this system, for which there are precedents and experiences in several countries, has led to major changes in the economic structure. The Mexican government has based the establishment of its emissions trading system on these lessons learned.

The JI and CDM are project-based compensation mechanisms that enable carbon credits to be obtained with ex-post verification of the emission reductions achieved. Additionally, they seek to promote technological and financial transfers through international investment, whereas emissions trading is a reduction mechanism with pre-set emission limits for a period of time determined by the competent authority so that the reduction depends on the size of the cap, distributed in emission quotas, thus building on the ex ante allocation of emission allowances that can be traded on the market (Ibarra 2019).

The CDM was an innovative tool that involved developed and developing countries in financing climate action. The CDM is an existing mechanism, in which Mexico has had extensive participation. Currently, in the Latin American region, Mexico ranks second in the number of registered projects with 192, especially in the areas of methane recovery, waste management and recovery, renewable energy, energy efficiency, industrial processes, and agriculture (UNFCCC 2020).

In general terms, the flexible mechanisms have the peculiarity of integrating the environmental variable into economic systems by introducing market rules in favor of the environment, facilitating the fulfillment of commitments at a low economic cost, as an incentive, with the advantage of being voluntary and introducing the private sector without displacing State responsibility. They are therefore linked to national policies and measures of supplementary nature - an intended feature of the Protocol (Articles 6(d) and 17 of the Protocol). This means that under no circumstance should these mechanisms supplement national measures to comply with the obligations assumed and are, therefore, not a means of compliance in stricto sensu, but rather an aid so that States comply (Saura 2003; Ibarra 2012).

The Kyoto Protocol helped enable developed and developing country governments to adopt climate policies and laws, and propelled some industries and companies to take into account the environmental variable, specifically climate change, in decisionmaking about their investments. However, this legal instrument was ineffective in terms of global mitigation (Salinas 2017) because, despite the fulfillment of quantified commitments (European Environment Agency 2017), the steady global increase in the volume of GHG emissions continued, aggravating the climate problem and failing to meet the UNFCCC's target, largely due to the Protocol's original structural 
deficiencies. ${ }^{3}$ This led to the adoption of a new framework of obligations for States: the Paris Agreement.

\section{The Paris Agreement NDCs}

The Paris Agreement, in addition to achieving the Convention's objective, aims to strengthen the international response to sustainable development with low GHG emissions with the goal of maintaining the average global temperature increase well below $2{ }^{\circ} \mathrm{C}$ with respect to pre-industrial levels, limiting the increase to $1.5^{\circ} \mathrm{C}$ (Article 2). To this end, the Agreement changes the strategy at the mitigation level, adopting "voluntary" commitments from developed and developing countries, replacing the top-down scheme with a bottom-up scheme. The commitments are specified in the instrument of Nationally Determined Contribution (NDC) so that emission reduction is not limited to some countries, but to all, implying broad coverage in which each State establishes its own contribution to mitigation and determines the means to achieve it.

In this regard, the Mexican government assumed two types of mitigation commitments in its NDC: unconditional (with its own resources) and conditional (with additional resources and technology transfer through international cooperation). In terms of the former, it committed to reducing $25 \%$ of its GHGs and short life climate pollutants (SCCP) by 2030, which implies: (a) A 22\% baseline reduction in direct emissions of carbon dioxide, methane, nitrous oxide, and fluorocarbon gases; and (b) A $51 \%$ reduction in black carbon particle emissions. This commitment incorporates a peak in net emissions for 2026; thereafter net emissions should start to decline.

Concerning conditional commitments, the objective expressed above extends to a $40 \%$ reduction in GHGs and HCVs by 2030, including: (a) GHG reductions of up to $36 \%$; and (b) Reductions in black carbon emissions to $70 \%$. The commitment is conditional on a global agreement, including, for example, provisions for an international carbon price, tariff adjustments for carbon content, financial cooperation, and technology transfer, among others. ${ }^{4}$

\footnotetext{
${ }^{3}$ Under the regulatory scheme of the Kyoto Protocol, the turning point was precisely the nonimposition of quantifiable emissions reduction commitment on the States considered as developing countries (not included in Annex I of the UNFCCC), countries that, as principally China and India are currently among the main emitters. However, this does not mean that developed countries are now the ones who emit the least, since the United States, the 28 countries of the European Union (mainly Germany), Russia, Japan and Canada are among the 10 territories with the most $\mathrm{CO}_{2}$ emissions including, of course, the territories of the emerging economies of China and India.

${ }^{4}$ Prior to the 21st meeting of the Conference of the Parties to the UNFCCC (COP21), at COPs 19 and 20 in accordance with its first decision (1/CP.19 and 1/CP.20), all Parties were invited to communicate to the UNFCCC Secretariat their Intended Nationally Determined Contribution (INDC), with the aim of being brought for negotiation at COP21. With the implementation of the Paris Agreement, the approved INDCs were considered official and thus acquired the name Nationally Determined Contribution (NDC). Mexico submitted its NDCs on 27 March 2015, becoming the first developing country to do so.
} 


\section{Article 6 of the Paris Agreement}

Achieving the objective of the Paris Agreement depends on the effective implementation of the mitigation commitments of the NDCs and their progressive ambition. Although the Agreement does not stipulate an obligation to coercively fulfill such commitments, Parties shall pursue domestic mitigation measures, with the aim of achieving the objectives of such contributions, in accordance with Article 4(2). In this regard, the measures adopted should aim at the decarbonization of the economies, which will lead to radical changes in production sectors, the promotion of energy efficiency, the introduction of new low-carbon technologies, investment in technological innovation, changing consumption patterns, etc. This will require the promotion and/or imposition of diverse measures in national climate policies, where the use of economic instruments has increased due to its flexible and profitable framework. Specifically, emissions trading has proliferated geographically. Its introduction and development was the legacy of the Kyoto Protocol, which some scholars consider to be its great merit (Baron and Philibert 2007; Sanz 2009; Philibert 2005).

Article 6 of the Paris Agreement does not specifically mention the flexible mechanisms of the Protocol, however, it alludes to them implicitly as we will see next. Furthermore, it is assumed that they remain applicable as they do not conflict with the content of the Agreement, in accordance with Article 30 of the 1969 Vienna Convention on the Law of Treaties (Salinas 2017).

The execution of Article 6 is considered fundamental to achieve the Agreement's objectives in compliance with the NDC's mitigation targets and increased ambition. However, to date, the State Parties have not been able to agree on its rules of application, due to the fact that its content has become controversial as it requires common guidelines for the use of cooperative approaches on a voluntary basis, among which are market mechanisms. The above is drawn from the core points of Article 6, paragraphs 2 and 4, to which we will refer without being exhaustive but with the objective of pointing out elements that the Mexican government should address in its participation in the carbon markets and offsets.

\section{Article 6(2) of the Paris Agreement}

Article 6(2) states that:

Parties shall, where engaging on a voluntary basis in cooperative approaches that involve the use of internationally transferred mitigation outcomes towards nationally determined contributions, promote sustainable development and ensure environmental integrity and transparency, including in governance, and shall apply robust accounting to ensure, inter alia, the avoidance of double counting, consistent with guidance adopted by the Conference of the Parties serving as the meeting of the Parties to this Agreement.

This section states that to facilitate compliance with the commitments assumed in the NDCs, units known as Internationally Transferred Mitigation Outcomes 
(ITMOs) may be transferred between State Parties through mechanisms such as carbon markets. It is also established that projects and programs that participate voluntarily in cooperative approaches to generate ITMOs, in addition to being profitable, must promote sustainable development and guarantee environmental integrity, as well as transparency.

The principle of environmental integrity implies recognizing the repercussions of human activity on ecological systems, respecting the limits of the regenerative capacity of ecosystems, and avoiding irreversible damage to populations and plant and animal species (actions that lead to irreplaceable losses, such as the extinction of endangered species). At the same time, it implies protecting areas internationally recognized for their ecological, cultural, or historical value (International Institute for Sustainable Development 1994). For environmental integrity to exist, the environmental variable must first be incorporated in decision-making, which is undoubtedly a state responsibility, whose level of incorporation will depend on the degree of maturity of the political and economic systems. That is, in particular, the strength of the planning, management, and resource allocation structure. The strengthening of the rule of law in environmental matters is required; a key element for the protection, conservation, and restoration of environmental integrity, without which environmental governance and compliance with national and international rights and obligations could become arbitrary, subjective, and unpredictable (UICN 2016).

In view of the multiple legal, economic, political, social, environmental, and institutional differences-which are reflected in the diversity of the NDCs presented by the State Parties to the Paris Agreement - the demand for effective enforcement of environmental integrity is of great relevance when approving projects and programs that ensure real and measurable GHG emission reductions traded in international markets.

While the Paris Agreement does not define environmental integrity, Schneider and La Hoz Theuer (2019) identify four main factors to ensure that global GHG emissions do not increase as a result of transfers and that environmental integrity is not undermined:

1. Accounting for international transfers.

2. Quality of units.

3. Ambition and scope of the mitigation target of the transferring country.

4. Incentives or disincentives for future mitigation action.

On the other hand, Article 6(2) urges that two countries should not claim the same emission reductions for the fulfillment of their respective mitigation targets, which would imply that the reduction of one tonne of emissions would be counted in favor of two countries and not just one. Preventing double counting or double claiming requires strong and robust monitoring, reporting, and verification (MRV) systems to demonstrate net emission reductions, which is complemented by the Transparency Framework under Article 13 of the Paris Agreement.

Schneider and La Hoz Theuer (2019) point out that sound accounting is a prerequisite for both ensuring environmental integrity and making accounting for international transfers representative of Parties' mitigation efforts over time. They also 
establish that in order to prevent cumulative global emissions from increasing, it is essential that there be adequate accounting of the reductions or removals of emissions from activities with temporary results, such as in the land-use, land-use change, and forestry sectors or in the case of geological storage of $\mathrm{CO}_{2}$. Regarding the other elements, the authors note that the quality of the transfer units will depend on criteria similar to those of the accreditation systems used in the flexible mechanisms of the Kyoto Protocol. In turn, they point out that the quality of the units is linked to the mitigation objectives, the more ambitious the objectives, the higher the quality.

Finally, they highlight the international carbon markets as instruments that can provide both incentives and disincentives for future mitigation actions, since they consider that for the countries acquiring carbon units the market is an incentive that allows for reducing costs in order to achieve more ambitious objectives, but the system could discourage selling countries from setting more ambitious future mitigation targets, in order to sell carbon units at a better price in order to obtain more benefits from the transfer units internationally. This is because the system responds to supply and demand (the lower the volume of carbon units, the higher the price).

Although the mitigation objectives of the NDCs are established outside the market and cannot be modified once they are presented under the framework of the Paris Agreement, in the updates of the future NDCs of the country that sells carbon units could consider the prices of carbon units in the market and if they are high, it is very likely that they do not want to saturate the said market with more units to preserve their price, so their level of ambition in mitigation actions could be lower.

Hence, it is appropriate to link emissions trading systems internationally between countries with similar levels of ambition. Also, these authors suggest that the Parties could decide to establish requirements for participation in international transfers under Article 6 that provide incentives for countries to expand the scope of their NDCs, for example, by limiting these transfers to emission reductions generated by sectors or gases covered by the selling country's NDCs or, alternatively, requiring countries to commit in the future to expand the scope of their NDCs to targets in all economic sectors in order to be able to participate in Article 6.

Regarding the international carbon markets, Zapf et al. (2019) consider that a global market is an adequate instrument for achieving the common commitment of the Paris Agreement. To this end, they point out that, in addition to adopting the cap and trade scheme, the introduction of this system must be uniform and cross-sectoral with a specific politically agreed design. When this is an instrument subject to speculation, the best that can be achieved is that the overall costs of reducing emissions are minimized as much as possible, while ensuring that global $\mathrm{CO}_{2}$ emissions remain within a certain carbon budget.

\section{Article 6(4) of the Paris Agreement}

In connection with the previous section, paragraph 4 states the following: 
A mechanism to contribute to the mitigation of greenhouse gas emissions and support sustainable development is hereby established under the authority and guidance of the Conference of the Parties serving as the meeting of the Parties to the Paris Agreement for use by Parties on a voluntary basis. It shall be supervised by a body designated by the Conference of the Parties serving as the meeting of the Parties to the Paris Agreement, and shall aim:

(a) To promote the mitigation of greenhouse gas emissions while fostering sustainable development;

(b) To incentivize and facilitate participation in the mitigation of greenhouse gas emissions by public and private entities authorized by a Party;

(c) To contribute to the reduction of emission levels in the host Party, which will benefit from mitigation activities resulting in emission reductions that can also be used by another Party to fulfill its nationally determined contribution; and

(d) To deliver an overall mitigation in global emissions.

This section anticipates the development and emergence of a new system based on and as a successor to the CDM, known as the Sustainable Development Mechanism (SDM). It is expected to adopt all the positive experiences of the CDM, but also to address its shortcomings, such as the inadequate use of additionality and the lack of project sustainability (their inequitable geographical distribution and compensation ${ }^{5}$ as opposed to a reduction scheme) (Ibarra 2012).

In the implementation of projects under the CDM scheme, additionality in relation to the baseline scenario, also called business-as-usual (BAU), linked to the need to ensure that real, measurable, and certifiable GHG reductions or removals are generated, has been one of the most discussed issues (Greiner and Michaelowa 2003; Schneider 2009; Cames et al. 2016; Fischer 2005) as it is fundamental to ensure environmental integrity and thus the effectiveness of global climate action since additionality requires that any mitigation or removal activity considered for a marketbased mechanism must demonstrate that the reduction of GHG emissions or the increase in GHG removals are greater than what would occur if the project activity were not carried out.

Additionality applied to the new Paris Agreement's liability scheme implies ensuring that activities based on market mechanisms are truly additional to host countries' CDMs. It also implies that those activities should generate real GHG reductions. Because countries and other participating entities use dummy units to meet their mitigation obligations, through offsets, an overall increase in emissions will be generated instead of a reduction, altering the environmental integrity of the Agreement, hence the importance of ensuring additionality. However, its verification is one of the most difficult methodological problems, but it is essential to address it within the institutional and legal framework of the verification system (Michaelowa et al. 2019).

Following this order of ideas, additionality is an integral concept to ensure sustainable development, since it cannot be determined by the economic factor alone, that is

\footnotetext{
${ }^{5}$ The CDM is not considered to be an instrument of global emission reduction, but rather an instrument of compensation, since the emissions made in excess in the territory of developed countries are compensated with those avoided in the projects implemented in developing countries.
} 
to say, by cost-benefit criteria of monetary value, since the implementation of activity for a market mechanism should also promote environmental and social benefits in addition to being an important means of technology transfer.

In this regard, the experience developed in CDM projects is relevant, since many projects lacked sustainability (Schneider 2007) because they generated negative impacts, either social (conflicts over land tenure, restrictions on access to goods and services for local communities, population displacement, evictions, and expropriations, among others, with serious human rights implications), environmental (loss of biodiversity, habitat destruction, alteration of ecosystems, soil erosion, increased risk of fire, etc.), economic (loss of long-term benefits, increased illegal economic activities), cultural, and/or religious (Ibarra 2012). The concept of sustainable development in practical terms is highly debatable in the CDMs, especially in determining the extent to which it has been achieved. This led to the acceptance of projects with negative effects that were especially economically beneficial to developed countries by generating CERs (Muller 2007).

Currently, formal modalities and procedures for the new mechanism proposed in Article 6(4) are being negotiated at the Conference of the Parties to the Country Agreement, for which the experience gained from the flexible mechanisms of the Kyoto Protocol should undoubtedly be valued and go even further in obtaining results. Michaelowa et al. (2019) point out that in the face of the new paradigm changes, the activities proposed under the scheme of the new mechanism, could not only be evaluated in terms of their sustainability, but rather in terms of their transformative potential. This is to say, toward a transformational development which could complement or even replace the proof of additionality. The criterion of transformational change is a great challenge (Michaelowa et al. 2019), however, it is necessary to confront it given the climate emergency we are facing.

In general terms, Article 6 requires a great deal of negotiation between the Parties to establish international rules for the implementation of the new mechanisms. At the same time, it determines their transition with the existing mechanisms under the Kyoto Protocol, such as with the regional and national carbon markets that are increasing in number and in operations, which can undoubtedly contribute to implementing the new mechanisms of international cooperation.

\section{National Legal Basis}

Regarding climate change, over the years the Mexican government has adopted a legal and institutional framework to comply with its international commitments. In this process of gradual and progressive advancement, the emissions trading system is currently regulated as a mandatory instrument, which is expected to contribute to achieving the mitigation objectives of the CDMs presented in the provisions of the Paris Agreement.

However, the application of the cap and trade scheme is not a novelty in the Mexican system. From 2001 to 2005, Petroleos Mexicanos (PEMEX) voluntarily 
implemented an internal market for carbon emission permits with the technical support of Environmental Defense, a non-governmental organization from the United States.

PEMEX began to quantify its emissions in 1997 and established goals for reducing $\mathrm{CO}_{2}$ emissions by $1 \%$ with respect to 1999 levels for the 2001-2003 period. To achieve this, it operated the internal commercialization of emission permits in which 25 Business Units (PEMEX industries with the highest carbon emissions) participated and to which permits equivalent to one ton of $\mathrm{CO}_{2}$ were granted. For the coordination and development of the market, the Corporate Environmental Protection Audit was created; online market operations were carried out in the Transaction Registration System developed by PEMEX. The mechanism stimulated competition among the Business Units within the market to reduce their emissions and reach the goal imposed by the same company, in which each Unit developed better operational practices and executed projects that were cost-effective and cost-beneficial in the reduction of emissions to obtain a surplus in the permits granted, sell them on the market and make a profit, as well as obtaining business experience for networking purposes with future global markets (Gómez 2004). The results were favorable since, in 2002, an accumulated emissions reduction of $11 \%$ was achieved with respect to the base year (1999). This is equivalent to almost 5 million tons of $\mathrm{CO}_{2}$ (Fernández and Martínez 2003). However, with the Kyoto Protocol entering into force in 2005, the market ceased to function and was replaced by CMD projects; the company only registered one project in 2012, which to date has not entered the stage of soliciting the corresponding certificates ${ }^{6}$ (UNFCCC 2020).

\section{Economic Instruments in the LGEEPA}

Legally, the economic instruments were introduced in the General Law of Ecological Balance and Environmental Protection (Ley General de Equilibrio Ecológico y Protección al Ambiental or LGEEPA) ${ }^{7}$ by means of reforms published in the Official Gazette of the Federation (DOF) on 13 December 1996; until then, environmental enforcement had been based on a system of direct regulation (command and control): permits, inspections, and sanctions. However, it was considered that it should be complemented by other types of instruments to achieve the environmental policy objectives.

According to the explanatory memorandum of the 1996 reform initiative, the indirect regulation based on economic instruments was considered ideal for giving effect to two fundamental principles of environmental policy:

(1) Whoever pollutes, makes excessive use of natural resources, or alters the ecosystems must assume the costs inherent to their conduct.

\footnotetext{
${ }^{6}$ Project 4966: Waste Energy Recovery Project at PEMEX TMDB.

${ }^{7}$ Published in the Federal Official Gazette (DOF) on 28 January 1988.
} 
The Polluter Pays Principle was introduced in 1972 by the members of the Organization for Economic Cooperation and Development (OECD), which postulates that the polluter should bear the full costs of any environmental damage caused by the production of goods and services, which implies the internalization of environmental degradation costs as a negative externality (OECD 1975) ${ }^{8}$ By means of this principle, it is intended to compel the producer of goods and services to internalize the externality, absorbing the costs of production, as well as the environmental ones (Butze 2006).

(2) Whoever conserves resources and invests in ecological conservation, reconstructing the environmental capital of the nation, should receive a stimulus or compensation.

In contrario sensu, whoever protects and conserves obtains an economic benefit when referring to who should be stimulated or rewarded for protecting the environment.

In consideration of the above, the LGEEPA regulates in Section III the economic instruments and defines them in its Article 22, first paragraph, as those of:

Regulatory and administrative mechanisms of a fiscal, financial, or market nature, through which people assume the environmental benefits and costs generated by their economic activities, encouraging them to carry out actions that favor the environment.

The Law distinguishes between fiscal, financial, and market instruments, with respect to the latter, the fourth paragraph establishes that they are:

The concessions, authorizations, licenses, and permits that correspond to pre-established volumes of emissions of pollutants into the air, water, or soil or that establish limits to the exploitation of natural resources [...].

The prerogatives derived from economic market instruments shall be transferable, nontaxable, and remain subject to the public interest and the sustainable use of natural resources.

The emissions trading system has its legal basis in this provision, which allows for the establishment of permits or transferable rights in the market through the prior establishment of an air pollutant emissions limit by the State. The provision is also extended to the compensation system. However, the Law only recognizes this instrument legally but without giving it a mandatory nature. Additionally, the Law, although it provides for the prevention and control of air pollution (Articles 110 to 116), does not focus on climate change and its complex problems, hence the need for specific legislation.

\footnotetext{
${ }^{8}$ The controversy of this principle has been around its adequate application and its link to the valuation of the real costs of environmental degradation; distorting on multiple occasions its pragmatic background by interpreting it as "a right to pollute" through payment. On the other hand, acceptance and application of the principle in international relations still generates discord among States.
} 


\section{The Economic Instruments in the LGCC}

Mexico was the first developing country to adopt a law on climate change, published in the DOF on 6 June 2012, and in force as of 10 October of the same year in accordance with its First Transitory Article.

The General Law on Climate Change (Ley General de Cambio Climático or LGCC), in accordance with its Article 1, regulates the provisions of the Political Constitution of the United Mexican States (Constitución Política de los Estados Unidos Mexicanos or CPEUM) on environmental protection, sustainable development, and the preservation and restoration of ecological balance. 2:

The LGCC has among its objectives, in accordance with its stipulations in Article

- Guarantee the right to a healthy environment.

- Regulate the emissions of greenhouse gases and compounds.

- Regulate actions for the mitigation of climate change.

- Promote education, research, development, and transfer of technology and innovation, and dissemination in the field of climate change mitigation.

- Promote the transition to a competitive, sustainable, low-carbon economy that is resilient to the extreme hydrometeorological events associated with climate change.

- Establish the bases so that Mexico contributes to the fulfillment of the Paris Agreement.

Likewise, the Law determines an indicative target or aspirational goal for the reduction of emissions in the Second Transitory Article, consisting of a $30 \%$ reduction of GHG emissions by 2020 with respect to the baseline, and conditioned to economic and technological support, a reduction of $50 \%$ by 2050 based on what was emitted in 2000. At the same time, the Third Transitory Article establishes that the actions taken in the matter of mitigation should reach the following aspirational goals and indicative deadlines: Promotion of electricity generated by means of clean energy sources by at least $35 \%$ by the year 2024; which constitutes an essential component to reach the emissions reduction goals committed to in the NDC of Mexico, which are in line with the conditional goal set forth by this law.

Regarding the NDCs, it should be noted that those presented by the Mexican government in 2015 were based on the following instruments:

- General Law on Climate Change (LGCC, adopted in 2012)

- National Climate Change Strategy, 10-20-40 Vision (Estrategia Nacional de Cambio Climático, Visión a 10-20-40, adopted in 2013)

- Carbon Tax (Impuesto al Carbono, implemented in 2014)

- National Emissions Register (Registro Nacional de Emisiones or RENE, created and launched in 2014)

- Energy Reform (Reforma Energética, laws and regulations adopted in 2013)

- National Inventory of Greenhouse Gas and Compound Emissions (Inventario Nacional de Emisiones de Gases y Compuestos de Efecto Invernadero, update 
presented in 2015 by the National Institute of Ecology and Climate Change (INECC) in compliance with Article 74 of the LGCC).

In view of the objectives, the LGCC determines the scope and content of national climate change policy, for whose orientation and implementation, in accordance with Article 58, the Special Climate Change Program, as well as the Nationally Determined Contributions (NDC), are among the planning instruments for the National Climate Change Strategy.

The LGCC establishes two guiding principles for action: adaptation and mitigation, both with medium- and long-term focuses. In terms of mitigation, Article 31 states that through planning and economic instruments, the policy should include a diagnosis, planning, measurement, monitoring, reporting, verification, and evaluation of national emissions; in response to which the National Inventory of Emissions of Gases and Greenhouse Compounds and the National Emissions Registry are instituted, the latter regulated by the LGCC's Regulations on the matter of the National Emissions Registry, published in the DOF on 28 August 2014.

The national policy on climate change determined, in accordance with Article 26 , section IX, that the use of economic instruments in mitigation encourages the protection, preservation, and restoration of the environment, and the sustainable use of natural resources, in addition to generating economic benefits for those who implement them.

The economic instruments are regulated in Chapter IX in Articles 91 to 95. They are defined in Article 92 and based on the concept of the LGEEPA, the variant is due to the objective of the LGCC, with respect to which it is indicated that through these instruments of fiscal, financial, or market character people assume the benefits and costs of the mitigation and adaptation to climate change, with the objective of encouraging them to carry out actions that favor achieving the objectives of the national policy on climate change.

The fourth and fifth paragraphs of the same Article, in accordance with the LGEEPA, state that market instruments are:

The concessions, authorizations, licenses, and permits that correspond to pre-established volumes of emissions, or that provide incentives to carry out actions to reduce emissions by providing alternatives that improve their cost-efficiency ratio.

The prerogatives derived from market economic instruments shall be transferable, nontaxable, and will be subject to the public interest.

In this sense, the Law shows the suitability of privileging the actions with the greatest potential for mitigation in a cost-efficient manner and that at the same time generate a collective benefit. This scheme contemplates the emissions trading system, the use of which was always considered in Article 94, but on a voluntary basis. It was not until the 2018 reforms to the LGCC that its implementation was stipulated as mandatory at the federal level. It should be noted that the Law gives the federation the power to create, authorize, and regulate emissions trading (Article 7, section IX), while the National Institute of Ecology and Climate Change is empowered to participate in its design (Article 22, section III). 
Economic instruments in general, and specifically market instruments, regulated by the provisions of the LGEEPA and the LGCC have their basis in Articles 4, 25 , and 27 of the CPEUM, to which we refer below.

Article 4 , in its fifth paragraph, stipulates the right to a healthy environment, which is the guiding principle of Mexican environmental policy, and therefore, of any instrument or measure adopted to achieve its objectives. Such is the case of market instruments. It should also be noted that maintaining the atmosphere in optimal conditions and free of excess pollutants, will guarantee the enjoyment of this right.

The first paragraph of Article 25 states that the Mexican government should guarantee comprehensive and sustainable economic development, in response to which the seventh paragraph establishes that, under the criteria of social equity, productivity, and sustainability, it will support and encourage businesses in the social and private sectors of the economy. But they will be subject to the modalities dictated by the public interest and the use of productive resources will be for the general benefit, seeking to preserve them and the environment.

Preservation of the chemical composition of the atmosphere through stabilization of the concentrations of GHG emissions to a level that avoids dangerous anthropogenic interference in the climate system is of public interest. Hence, the establishment of emission limits by the State for the productive sectors, through market instruments, is in the interest of the community and linked to the postulate of guaranteeing sustainable development, whose achievement requires in-depth structural changes where the general interest prevails over the individual.

As for Article 27, in its third paragraph, the principle of the social function of private property is consecrated, which is subject to the limitations dictated by the State in benefit of environmental protection. Market instruments restrict (does not imply deprivation) rights under the protection of the general interest (Sanz 2007). Rosembuj (2005) points out that, in the establishment of social order, there exist two opposing principles: the principle of individual freedom, supported by the right to property; and the second, the principle of equality of all humans, where the beholder of social wellbeing is the State. It is precisely in the adequate concordance of both principles where the ideal environmental protection lies.

\section{The Emissions Trading System in the LGCC}

On 13 July 2018, the Decree in which various provisions of the LGCC are amended and added was published in the DOF, including the reforms to Articles 94 and 95, through which the creation, authorization, and regulation of the emissions trading system were consolidated.

In response to these modifications, Article 94 mandates the establishment of a progressive and gradual emissions trading system to promote the reduction of emissions at the lowest possible cost, in a measurable, reportable, and verifiable manner and without compromising the competitiveness of the participating sectors facing 
international markets. In turn, Article 95 stipulates the possibility to network with carbon markets from other countries in order to carry out operations and transactions.

Likewise, it was established in the Second Transitory Article that the system in its operational phase would remain subject to the adoption of the preliminary bases for a test program with a validity of thirty-six months, without economic effects for the participating sectors and without harming their business competitiveness. This provision was the guideline for formalizing the system's pilot phase.

The preliminary bases for the Test Program of the Emissions Trading System were established by means of an Agreement published in the DOF on 1 October 2019; subsequently, in compliance with the provisions of the Agreement, the Secretariat of the Environment and Natural Resources (SEMARNAT) distributed notices on 27 November 2019 in regards to the emissions cap and the sectoral allocation of allowances. In accordance with these instruments, the core elements of the system are stipulated in its preparatory phase (Table 6.1).

Table 6.1 Mexican emissions trading system. preparatory phase

\begin{tabular}{|c|c|}
\hline Market type & Cap and trade \\
\hline Object & Emission allowances and offsets \\
\hline Allocator & The State through SEMARNAT \\
\hline Allocation & $\begin{array}{l}100 \% \text { free allocation in test phase (grandfathering } \\
\text { criterion) }\end{array}$ \\
\hline Actors & Transactions between participating sectors \\
\hline Sectors to support emissions with quotas & Energy and Industry \\
\hline Participation threshold & $\begin{array}{l}\text { Applicable to facilities whose annual emissions are } \\
\text { equal to or greater than } 100,000 \text { tons of direct carbon } \\
\text { dioxide emissions from fixed sources, as reported in } \\
\text { the National Emissions Registry (RENE) }\end{array}$ \\
\hline Phases & $\begin{array}{l}\text { Preparatory or pilot phases (test program) } \\
\text { Operational (after the test program) }\end{array}$ \\
\hline Territorial Scope & Federal \\
\hline Time frame & $\begin{array}{l}\text { Thirty-six-month pilot phase, which will start on } 1 \\
\text { January } 2020 \text { and end on } 31 \text { December of } 2022 \text {, } \\
\text { divided into two periods ( } 1 \text { January } 2020 \text { to } 31 \\
\text { December } 2021 \text { will correspond to the pilot phase; } \\
\text { between } 1 \text { January } 2022 \text { to } 31 \text { December } 2021 \text { will be } \\
\text { the transition phase from the Test Program to the } \\
\text { Operational Phase of the Emissions Trading System) }\end{array}$ \\
\hline Gases & $\begin{array}{l}\text { In the pilot phase only } \mathrm{CO}_{2} \text {, direct emissions from } \\
\text { fuel consumption and industrial processes }\end{array}$ \\
\hline Limit of use of offsets & Up to $10 \%$ \\
\hline Coercivity & Non-economic in pilot program \\
\hline Annual cap & $\begin{array}{l}271.3 \text { million allowances for } 2020 \\
273.1 \text { million allowances for } 2021\end{array}$ \\
\hline
\end{tabular}


In order to comply with the goals indicated in its NDC, the Mexican government opts for the obligatory execution of the emissions trading system with the goal of promoting the reduction of emissions at the lowest possible cost. This emissions trading system, like other economic instruments, does not substitute the direct control measures related to the participating facilities, rather, it is complementary.

It is important to note that the emissions market does not privatize the collective ownership of the atmosphere (a natural resource of common use), but rather, legally creates, with respect to this asset, usage rights (emission allowances) that are marketable under the control of public administration in order to safeguard the function and quality of the protected good. The system self-imposes a legal obligation on the participating sectors to support their economic activity with these allowances during a determined compliance period. The emissions trading legalized in our system, therefore, allows limits to be placed on the freedom to emit $\mathrm{CO}_{2}$ into the atmosphere at the facilities of the sectors indicated by the legal standard (energy and industry, according to the classification provided for in the RENE Regulation), who may continue exercising their polluting activity, but only in the amount established by the number of allowances allocated or obtained in the market. The system does nothing more than transforming the freedom of use of the atmosphere into a right to use it with its respective restrictions and obligations for its holder; with which the quantitative problem of emissions is addressed to qualitatively protect the natural resource.

\section{The Importance of a Reduced Cap}

Emissions trading seeks to flexibly incentivize the participation of the sectors involved in order to achieve climate objectives. Its establishment constitutes a direct regulation, while eliminating rigidities. Hence, the system as an emissions control technique forms part of the administrative management sphere, where the market does not take precedence over regulation, but rather is born thanks to it (Sanz 2014). The system is in itself an economic instrument wrapped in a legal system since it not only complies with market rules, but also involves legal regulation, whose ultimate aim is the protection of atmospheric quality on the basis of sustainable development. Public intervention in the system's design is necessary to achieve the climate objectives. Reaching the quantified result depends on the authorized emissions cap and the allowances allocated by the State. In this sense, it is indispensable in the legal system to ensure that it is possible to trade below this cap but not exceed the maximum limit of permitted emissions, with which it will be possible to have certainty over the proposed results.

In this regard, the cap established by SEMARNAT is not in line with the structural objective of the system, as can be seen (Table 6.1) from 2020 to 2021, as it increases instead of decreasing. The cap as a core element must ambitiously decrease in order for it to be effective and have environmental integrity while the transition toward lowcarbon growth is encouraged. Otherwise, the system will only have economic effects. 
These types of markets operate with absolute objectives by establishing a perfectly fixed and assured maximum limit on emissions that prevent them from increasing (Lefevere 2005). A cap with an increasingly reduced limit is the means by which the first condition for a market is generated: the scarcity of emission allowances, which is created by the public administration at the moment of setting the maximum offer by establishing an emissions limit (Sanz 2014) and with which the allowances acquire a major economic value that internalizes the environmental cost.

The system designed in Mexico with a cap that increases instead of decreasing is due to the fact that the climate mitigation targets are relative to a BAU scenario in which emissions increase, that is, they are not established in absolute terms. On the other hand, the increased cap of the Mexican system is linked to the expectations of economic growth in which the expansion of the production of some participants is expected, as well as the incorporation of new participants to the market, which is related to the peak of net emissions for the year 2026 indicated in the unconditional mitigation commitments provided in the Mexican government's NDC.

The above is positioned within the scope of the discussion of the right to development. However, it should be noted that the current world economic development is not sustainable and cannot be a model to follow, countries like Mexico cannot repeat the same mistake, they must develop but under the scheme of sustainability and the guarantee of environmental integrity that entails changing the current patterns of the prevailing economic development model. Hence, it is essential to look for development alternatives that generate radical changes linked to the reduction of $\mathrm{CO}_{2}$ emissions and therefore both to the progressive reduction of the cap in an emissions trading system.

\section{Free Allocation and the Polluter Pays Principle}

The allocation of allowances to regulated facilities is a transcendent issue since each allowance has an economic value that forms part of the assets of the operation/facility, hence a smaller or larger allocation of allowances has major economic implications, where the allocation method generates different impacts on the facilities, sectors, and national economy (Del Río González 2004).

During the trial period in the Mexican system, the allocation of allowances was stipulated free of charge through the grandfathering method, that is, based on historical information reported to RENE. In this regard, we can refer to the fact that acquired allowances to use the atmosphere were recognized.

The free allocation of allowances granted by the State, in a preparatory phase, is more widely accepted among facilities subject to the obligation to support their emissions with quotas. However, Antunes (2006) considers that an emissions market based on this type of allocation is a real violation of the Polluter Pays Principle since it gives polluters an economic advantage by assigning them a valuable title free of charge, which will have a certain price on the market and with which several polluters would consequently be able to profit from obtaining certain economic gains. 
In this regard, Del Río González (2004) points out that regardless of what the initial allocation of allowances was, what matters is the optimal final result of the purchase and sale of allowances among the participants, that is, in a comprehensive view. In this regard, Sanz (2007), with whom we agree, considers that emissions trading in itself is a system that if the Polluter Pays Principle is applied, since any polluter who needs more allowances, apart from those allocated, will have to resort to the market to obtain, by means of payment, additional allowances that will enable them to use the atmosphere to dump their emissions while still respecting the established limit. Or, in the event that the purchase of allowances is more onerous, or if they are in short supply on the market, they must make the necessary adjustments so that their emissions match the allowances received, which implies a cost assumed by the facility concerned. In this case, the polluter bears the costs of carrying out the measures imposed by the public authority to meet the emission reduction targets.

\section{Legal Nature of Emission Allowances}

The third Article, section IV, of the preliminary bases of the Emissions Trading System Pilot Program defines the emission allowance as:

The administrative instrument issued by the Secretariat that grants the right to emit one ton of carbon dioxide during a given compliance period.

Legally, it is an administrative act that grants a subjective right. A holder has the power to use one ton of $\mathrm{CO}_{2}$, as opposed to the obligation to reduce their emissions; whose extraordinary reduction allows them to not use that allowance, to which they could obtain an economic benefit at the time of selling it to those who require extra allowances in order to comply with their obligations. In this way, the right holder obtains two options of use, depending on whether an action or an omission is carried out. In any case, a benefit is obtained, since if they emit the permitted amount, they are simply meeting their acquired allowance. If they choose not to emit and exercise their right to transfer the unused designated quota, the benefit is greater, since it allows for the possibility of obtaining an economic asset with respect to the good for sale on which the negotiated allowances fall (the emission). The price for which it is sold should be high given its scarcity when carrying out production activities due to the emissions limit established for the compliance period. This is in benefit of the ultimate goal, which is the protection of atmospheric quality (Ibarra 2012). In this context, allowances can be classified as subjective "administrative" rights, because they are rights created by the legal norm and assigned through an administrative act, with respect to which the "authentic interpretation" that establishes the preliminary bases themselves is considered to be unsuitable, and will, therefore, be subject to the interpretation established in practice.

On the other hand, it is important to emphasize that this right recognized in the legal system does not imply, nor can it imply, a privatization or appropriation of the air (Pâques and Charneux 2004). In fact, at no time do the regulatory norms 
recognize the appropriation of the atmosphere. There is only one property right over the allocated emissions quota. However, it is a ownership regulated and limited by the administration (Sanz 2007) in terms of the following elements:

- Expiration: participants who properly comply in a timely matter with the obligation provided for in the previous paragraph, may use the surplus emission allowances they have in their account to carry out transactions or comply with their obligations in subsequent compliance periods during the Pilot Program (Article 22).

- Timing: allowances issued will only be valid for the Pilot Program (Article 23).

- Conditions for their management and monitoring in the market (Articles 25 to 32)

\section{Conclusion}

The implementation of emissions trading as a complementary tool to achieve GHG emissions reduction targets has become more popular due to its flexible and costeffective scheme. At the international level with the new Paris Agreement strategy in the plans of the mitigation commitments, replacing the top-down scheme with the bottom-up scheme, it is expected to lead to a better and more comprehensive result in the implementation of carbon markets. However, in the framework of Article 6 of the Agreement, operational rules with common guidelines for the use of cooperative approaches on a voluntary basis are still being discussed among the States Parties. Provisions that the Mexican government should take into account in its participation in the carbon markets and offsets. In this regard, the demand for the effective application of environmental integrity will result in great relevance when approving projects and programs that ensure real and measurable GHG emission reductions, that can be traded in international markets. For this, it is essential to take into account the experience gained in the flexible mechanisms under the Kyoto Protocol.

At the national level, the mandatory nature of the emissions trading system is relevant, since it is aligned with international provisions and requirements for a common front against the continuous and constant rise of GHG emissions. The preliminary bases of the system in its pilot phase determine its core elements, which should be stricter in order to achieve international and national commitments to real emission reductions. In this regard, the cap is particularly important as a fundamental element, which should establish decreasing limits so that it has effectiveness, environmental integrity, and to encourage the transition to low-carbon growth, otherwise, the system will only have economic effects. This is important since the quality of the allowances is linked to the mitigation objectives, the more ambitious the objective, the greater the quality. This will have international repercussions since it will be more convenient to relate to emissions trading systems with similar levels of ambition. 


\section{References}

Antunes T (2006) O Comércio de Emissões Poluentes à luz da Constituição da República Portuguesa. AAFDL, Lisboa

Baron R, Philibert C (2007) Climat, énergie et marchés de quotas échangeables. Revue De L'énergie $575: 17-25$

Butze W (2006) Permisos de contaminación negociables: Un instrumento de mercado para la regulación ambienta. Análisis Económico, XX I(48):257-288

Cames $M$ et al (2016) How additional is the clean development mechanism? Analysis of the application of current tools and proposed alternatives. Öko-Institut e.V, Berlin

Del Río González P (2004) Ventajas e inconvenientes de los métodos de asignación de derechos de emisión de $\mathrm{CO}_{2}$ en el contexto de la Directiva Europea de Comercio de Emisiones. Revista Interdisciplinar De Gestión Ambiental 6(71):16-30

European Environment Agency (2017) Annual European union greenhouse gas inventory 19902015 and inventory report 2017. EEA, Luxemburgo

Fernández A, Martínez J (Coords.) (2003) Avances de México en materia de cambio climático 2001-2002. SEMARNAT, INE, México

Fischer C (2005) Project-based mechanisms for emissions reductions: balancing trade-offs with baselines. Energy Policy 33(14):1807-1823. https://doi.org/10.1016/j.enpol.2004.02.016

Gómez S (2004) Mercado interno de permisos de emisiones de carbono. Estudio de Caso, Pemex. In: Martínez J, Fernández A (Comps.) Cambio climático: una visión desde México. México, Instituto Nacional de Ecología, Secretaría del Medio Ambiente, pp 447-453

Greiner S, Michaelowa A (2003) Defining investment additionality for CDM projects-practical approaches. Energy Policy 31(10):1007-1015. https://doi.org/10.1016/S0301-4215(02)00142-8

Ibarra R (2012) El Mecanismo de Desarrollo Limpio. Estudio crítico de su régimen jurídico a la luz del imperativo de sostenibilidad. Aranzadi, Pamplona

Ibarra R (2019) De la Convención Marco de las Naciones Unidas al Acuerdo de París: Una larga trayectoria científica, política y económica. In: Ibarra R (Coord.) Cambio Climático y Gobernanza: Una visión transdisciplinaria. Instituto de Investigaciones Jurídicas, UNAM, México, pp $3-36$

International Institute for Sustainable Development (1994) Trade and sustainable development. Principles. IISD, Canada

Lefevere J (2005) Greenhouse gas emissions trading: a background. In: Bothe M, Rehbinder E (eds) Climate change policy. Eleven International Publishing, Utrecht, pp 103-129

Michaelowa A et al (2019) Additionality revisited: guarding the integrity of market mechanisms under the Paris Agreement. Climate Policy 19(10):1211-1224. https://doi.org/10.1080/14693062. 2019.1628695

Muller A (2007) How to make clean development mechanism sustainable-the potential of rent extraction. Energy Policy 35(6):3203-3212. https://doi.org/10.1016/j.enpol.2006.11.016

OECD (1975) Le principe polleur - payeur. Definition, analyse, mise en oeuvre. OCDE, París

Pâques M, Charneux S (2004) Du quota d'émission de gaz à effect de serre. Revue Européenne De Droit De L'environmmement 3:266-278

Philibert C (2005) Transformer Kyoto. Esprit 318(10):28-42

Rosembuj F (2005) El precio del aire; Aspectos jurídicos del mercado de derechos de emisión. El Fisco, Barcelona

Salinas S (2017) El esfuerzo de mitigación de emisiones en el marco del régimen internacional contra el cambio climático. Estado de la cuestión tras el Acuerdo de París. In: García M, Amaya O (eds) Retos y compromisos jurídicos de Colombia frente al cambio climático. Universidad Externado de Colombia, Colombia, pp 23-53

Sanz I (2014) ¿Mercados para la protección del medio ambiente? Veredas Do Direito 11(21):11-30

Sanz I (Dir.) (2007) El mercado de derechos a contaminar. Régimen jurídico-público del mercado comunitario de derechos de emisión en España. Lex Nova, Valladolid 
Sanz I (2009) Los derechos de emisión y su aplicación en España. In: Martín JJ (Dir.) Hacia una política comunitaria europea en cambio climático y sus consecuencias para España. Universidad de Burgos, España, pp 197-218

Saura J (2003) El cumplimiento del protocolo de Kioto sobre cambio climático. Publicacions de la Universitat de Barcelona, Barcelona

Schneider L (2009) Assessing the additionality of CDM projects: practical experiences and lessons learned. Climate Policy 9(3):242-254. https://doi.org/10.3763/cpol.2008.0533

Schneider L, La Hoz Theuer S (2019) Environmental integrity of international carbon market mechanisms under the Paris Agreement. Climate Policy 19(3):386-400. https://doi.org/10.1080/ 14693062.2018 .1521332

Schneider L (2007) Is the CDM fulfilling its environmental and sustainable development objectives? An evaluation of the CDM and options for improvement. Öko-Institut e.V, Berlin

UICN (2016) Declaración Mundial de la Unión Internacional para la Conservación de la Naturaleza (UICN) acerca del Estado de Derecho en materia ambiental. Word Commission on Environmetal Law, Rio de Janeiro

UNFCCC (2020) CDM project search. https://cdm.unfccc.int/Projects/projsearch.html. Accessed 26 April 2020

World Resources Institute (1992) World resources 1992-93. Oxford University Press, New York

Zapf M, Pengg H, Weindl C (2019) How to comply with the Paris agreement temperature goal: global carbon pricing according to carbon budgets. Energies 12(15). https://doi.org/10.3390/en1 2152983

Open Access This chapter is licensed under the terms of the Creative Commons Attribution 4.0 International License (http://creativecommons.org/licenses/by/4.0/), which permits use, sharing, adaptation, distribution and reproduction in any medium or format, as long as you give appropriate credit to the original author(s) and the source, provide a link to the Creative Commons license and indicate if changes were made.

The images or other third party material in this chapter are included in the chapter's Creative Commons license, unless indicated otherwise in a credit line to the material. If material is not included in the chapter's Creative Commons license and your intended use is not permitted by statutory regulation or exceeds the permitted use, you will need to obtain permission directly from the copyright holder.

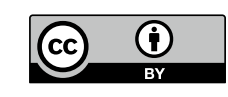

